\title{
The Relationship Between Internal Motor Imagery and Motor Inhibi- tion in School-Aged Children: A Cross-Sectional Study
}

\author{
Cuiping Wang ${ }^{1}$, Wei Li $^{1}$, Yanlin Zhou' ${ }^{1}$, Feifei Nan' ${ }^{1}$, Guohua Zhao ${ }^{2}$, and Qiong Zhang ${ }^{1}$
}

' Department of Psychology and Behavioral Sciences, Zhejiang University

2 Department of Neurology, Second Affiliated Hospital, College of Medicine, Zhejiang University

\begin{abstract}
Functional equivalence hypothesis and motor-cognitive model both posit that motor imagery performance involves inhibition of overt physical movement and thus engages control processes. As motor inhibition in internal motor imagery has been fairly well studied in adults, the present study aimed to investigate the correlation between internal motor imagery and motor inhibition in children. A total of 73 children (7-year-olds: 23, 9-year-olds: 27, and 11-year-olds: 23) participated the study. Motor inhibition was assessed with a stop-signal task, and motor imagery abilities were measured with a hand laterality judgment task and an alphanumeric rotation task, respectively. Overall, for all age groups, response time in both motor imagery tasks increased with rotation angles. Moreover, all children's response times in both tasks decreased with age, their accuracy increased with age, and their motor inhibition efficiency increased with age. We found a significant difference between 7-year-olds and 9-year-olds in the hand laterality judgment task, suggesting that the involvement of motor inhibition in internal motor imagery might change with age. Our results reveal the underlying processes of internal motor imagery development, and furthermore, provide practical implications for movement rehabilitation of children.
\end{abstract}

\section{KEYWORDS \\ internal motor imagery \\ motor inhibition \\ school-aged children \\ cross-sectional}

\section{INTRODUCTION}

Motor imagery is the ability to retrieve movement information from long-term memory and then manipulate it in working memory without actually performing the movement (Farah, 1984). Motor imagery plays an important role in motor performance, skill training, and motor recovery (Glover et al., 2020; see a review by Guillot et al., 2012).

Motor imagery can be performed using kinesthetic motor imagery (KMI) and/or visual motor imagery (VMI, Guillot et al., 2012). Kinesthetic motor imagery requires an individual to mentally rehearse performing a specific action, involving the perception of muscle contractions and stretching, while VMI requires an individual to imagine watching themselves or another individual performing a given action (e.g., Callow \& Waters, 2005; Guillot et al., 2009; Moran et al., 2012). Researchers suggest that VMI and KMI activate similar neural areas in the right supplementary motor area (BA6), but also show distinct activation. In particular, the VMI makes reference to the visual properties of visual perception, activating the dorsal (including occipital, parietal and frontal brain areas), and ventral stream areas (including the supplementary motor cortex and the precentral gyrus), while KMI involves greater motor simulation processes closely related to the form and timing of actual movements, activating subcortical areas, including the basal ganglia and cerebellum (Guillot et al., 2009; Jiang et al., 2015; Michelon et al., 2006). Visual motor imagery is divided into two

Corresponding author: Qiong Zhang, Department of Psychology and Behavioral Sciences, Zhejiang University.

E-mail: zhangqiongzgh@zju.edu.cn 
different and specific imagery modalities: internal and external VMI (Hall, 2001; Robin et al., 2020; Williams et al., 2012). For external VMI, participants have to imagine realizing a specific motor action as spectators of their own action (third-person imagery perspective), which can be likened to watching themself on a television or from another person's perspective. For internal VMI, participants have to mentally simulate performing a motor action through their own eyes (first-person imagery perspective), that is, as if they are viewing a camera that is placed on their foreheads whilst performing the movement (Hall, 2001). Studies report distinctively different brain activities when participants are asked to imagine internal and external perspectives (Jiang, et al., 2015; Seiler et al., 2015). Differentiating internal and external VMI can be essential for achieving optimal motor performance, thus providing beneficial motor imagery interventions (Robin et al., 2020). Notably, KMI is considered to be closer to an internal than an external VMI perspective (Guillot et al., 2009).

The biological and cognitive process underlying motor imagery are explained by many models and hypotheses. The functional equivalence hypothesis proposes that motor imagery and overt actions rely on overlapping brain areas such as the superior parietal, premotor cortex, primary motor cortex, basal ganglia, and cerebellum (e.g., Batula et al., 2017; Eaves et al., 2016; Guillot et al., 2009; Hardwick et al., 2018; Hétu et al., 2013; Hohlefeld et al., 2011; Jeannerod, 1994, 2001; Kim et al., 2017; Munzert et al., 2009; Vry et al., 2012). However, motor imagery involves a motor plan which is prevented from operating on the body. This mechanism allows individuals to evaluate the potential consequences of the future action and provides information for consciously monitoring their mental state, and controlling the overt action. Thus, it engages control processes (Jeannerod, 2001). Another account is the motor-cognitive model, which posits that motor imagery can be divided into two stages of action planning and real-time execution control (e.g., Elliott et al., 2001; Glover, 2004). At the planning stage, motor imagery and overt actions are functionally and neurologically equivalent (Glover \& Baran, 2017). However, the execution of motor imagery differs from that of overt actions, specifically, the latter use visual and proprioceptive feedback to handle and adjust ongoing movements, while the former is unable to use these sources of information due to the absence of physical movement. Hence, it is a necessary process to prevent overt movement during the execution of motor imagery (e.g., Cameron et al., 2009). Taken together, both theories note that motor inhibition is involved in cognitive processes of motor imagery (for a review see Guillot et al., 2012).

As for motor inhibition, also referred to as behavioral inhibition, response inhibition, and prepotent response inhibition, it is usually defined as the ability to process a prepotent motor response and withhold the response, which requires attending to task-relevant signals, planning, executing appropriate actions, and stopping actions rapidly even after initiation (Dutra et al., 2018). Recently, researchers have investigated the relation between motor inhibition and motor imagery and provided interesting findings. For instance, Angelini et al. (2015) asked participants to imagine themselves in a first-person perspective when performing a motor imagery task. That is, they were required to perform a KMI and visually imagine the movement as well. A putative inhibitory network was activated during the motor imagery task, which was partially overlapping with those activated when motor inhibition is needed. But research on the functional relation between internal firstperson perspective motor imagery and motor inhibition is very limited. Thus, the first goal of the present study was to add to that literature and to explore whether the ability of internal motor imagery correlates with the ability of motor inhibition.

Meanwhile, understanding the developmental trend of motor imagery in children can provide a window into the underlying processes of motor development. Evidence shows that children with congenital motor disorders, such as cerebral palsy and developmental coordination disorder, have problems in both motor imagery and motor control, but empirical studies on motor imagery training in children are scarce (Spruijt et al., 2015). Thus, it is necessary to study children's capacities of both motor imagery and motor inhibition and to provide a rationale for motor imagery training in children with motor impairments. Children's motor imagery ability is subjected to physiological maturation and development (Casey et al., 2005; Spruijt et al., 2015). Concurrently, children's motor imagery ability is also accompanied by cognitive and motor development. For example, executive control significantly improves between 6 and 8 years of age (e.g., Carlson et al., 2004; Ikeda et al., 2014; Moffitt et al., 2011), during which, motor planning ability, motor skills, and even motor imagery ability demonstrate prominent developmental changes (e.g., Caeyenberghs et al., 2009; Jongbloed-Pereboom et al., 2013; Smits-Engelsman \& Wilson, 2013; Souto et al., 2020). Studies investigating motor process involvement in motor imagery tasks report that younger children's motor imagery is more likely to be guided by motor processes (e.g., Funk et al., 2005), which accords with the Piagetian theory arguing that the role of motor processes in cognitive development decreases as a function of age. In contrast, studies suggest that motor processes are more prominent in adolescents (e.g., Conson et al., 2013). But few studies have explicitly examined the precise relationship between motor processes and motor imagery, particularly internal motor imagery in children. Hence, the second goal of the present study was to explore whether and how the development of internal motor imagery correlates with the development of motor inhibition.

In the present study, we used a hand laterality judgment task and an alphanumeric rotation task to assess KMI and VMI, respectively. The mental rotation task is a well-established paradigm to study the cognitive process of mentally rotating objects (Shepard \& Metzler, 1971). A variation of the classical mental rotation task, for example, a hand laterality judgment task, is often used to elicit KMI (e.g., de Lange et al., 2008; Parsons, 1994). In this task, participants are required to decide whether the depicted hand stimulus is a left or a right hand by pressing one of two buttons as fast as possible (de Lange et al., 2006; Parsons, 1994; Shenton et al., 2004; ter Horst et al., 2010). The hand stimuli are displayed in different angles of rotation and different directions, or different orientations (palm view or back view). Usually, response accuracy and RT are used as outcome measures. Response accuracy is indicative of the ability to solve the task correctly. Meanwhile, RT is indicative of the time spent in mentally rotating the hand stimuli back 
to the canonical orientation (i.e., the fingers pointing up), where the time increases with the deviation from the canonical orientation, which is taken as an indicator that participants use mental rotation to solve the task (Spruijt et al., 2017; Tomasino \& Gremese, 2016). Moreover, mental rotation of object-related stimuli (e.g., three-dimensional objects or alphanumeric characters) is used to elicit VMI as well (e.g., Osuagwu \& Vuckovic, 2014; Williams et al., 2006). Studies show that rotation of nonbody stimuli activate different neural areas from those activated by the rotation of hands (e.g., Kosslyn et al., 1998). Importantly, in the current study, we only presented single hands in a back view, following Williams et al. (2006).

To measure motor inhibition, a stop signal task and/or a go/no-go task are commonly used (Logan \& Cowan, 1984; Tiego et al., 2018). In the go/no-go paradigm, participants are presented with a series of stimuli and are required to respond when a go stimulus is presented and to withhold their response when a no-go stimulus is presented. In this task, a no-go stimulus is usually presented with a low probability (e.g., 25\%), where inhibiting a prepotency towards response execution at a preparatory or early activation stage is likely to occur. In the stop-signal paradigm, participants are required to respond to a go task as quickly as possible but inhibit their response to the go task when it is followed by an occasional stop signal. That is, the response is typically on its way to execution, but with low stop probability due to a greater demand on task inhibition processes (Johnstone et al., 2007). Researchers also assume that the motor inhibition in the go/no-go task is more likely to be automatic, which is more likely a reflection of associative learning, while the motor inhibition in stop-signal task is more likely to be controlled (Verbruggen \& Logan, 2008). According to the functional equivalence hypothesis and the motor-cognitive model, the motor inhibition involved in motor imagery might be more demanding and require greater control, thus, using a stop-signal task would be more appropriate.

Previous studies reported that children around 7 years old were able to perform internal motor imagery (Spruijt et al., 2015). In addition, children aged from 5 to 12 years old demonstrated an intensive development of motor inhibition (Šimleša \& Cepanec, 2015). Thus, we recruited children aged from 7 to 11 years old. We employed a child-friendly stop-signal task to measure motor inhibition, which is well examined and validated in cognitive development and individual differences research (Khng \& Lee, 2014; Verbruggen et al., 2013). Thus, we set out to investigate the development of internal motor imagery, and based on it, to further clarify the link between internal motor imagery and motor inhibition in children aged from 7 to 11 years old. Based on previous findings, we expected that internal motor imagery and motor inhibition abilities would improve with age. Furthermore, since evidence shows that KMI is rated as more difficult to mobilize than other types of imagery, perhaps motor inhibition would be more likely to be involved in KMI. Alternatively, if KMI requires more effort for mobilization, children might employ the VMI strategy across the two tasks, leading to a statistically significant correlation between motor imagery and motor inhibition in both tasks, and such a link might change as a function of age.

\section{METHODS}

\section{Participants and Procedure}

First, 90 right-handed children participated the experiment. Seventeen children were excluded from the analysis because of missing data (seven from the 7-year-old group, three from the 9-year-old group, and seven from the 11-year-old group) in either task. Thus, the final sample size was 73 , including 23 from the 7 -year-old group (11 females, age $=7.62 \pm 0.51$ years; 12 males, age $=7.43 \pm 0.37$ years), 27 from the 9-year-old group ( 14 females, age $=9.47 \pm 0.48$ years; 13 males, age $=$ $9.33 \pm 0.35$ years), and 23 from the 11-year-old group (11 females, age $=11.42 \pm 0.28$ years; 12 males, age $=11.58 \pm 0.34$ years . Children were recruited from a primary school in Hangzhou, China. All participants were in good health, with normal or corrected-to-normal vision. They were asked to report their handedness before they performed the tasks. All of them were from upper-middle-income families. The study was approved by the ethical committee of Zhejiang University, and a written consent form was obtained from parents and teachers for all of the participants.

\section{Measures}

All the children performed three tasks, including two mental rotation tasks and a motor inhibition task. The tasks were programmed in E-Prime 2.0 (Psychology Software Tools, INC.). Children were tested on a laptop with a resolution of $1024 \times 768 \mathrm{px}$ and a $14 \mathrm{in}$. TFT display in a one-to-one setting. All the tasks are described below.

\section{HAND LATERALITY JUDGMENT TASK}

In this task, stimuli were left or right hands portrayed from the back at $0^{\circ}, 45^{\circ}, 90^{\circ}, 135^{\circ}$, and $180^{\circ}$. Children were seated in front of the screen, with both hands straight in front of them, each hand resting on a key. The children were asked to determine whether pictures that appeared on the screen were left or right hands and to press the corresponding key as quickly as possible. They were observed by an experimenter to ensure they remained still except pressing the key throughout the task. There were 20 practice trials and 80 test trials (5 angles $\times 2$ hands) in total. Accuracy and RT were recorded.

\section{ALPHANUMERIC ROTATION TASK}

In this task, an uppercase $F$ or the number 5 were presented randomly in either normal or mirror-reversed orientation at five different angles, $0^{\circ}, 45^{\circ}, 90^{\circ}, 135^{\circ}$, and $180^{\circ}$. Participants were instructed to decide whether the stimulus was the correct or the wrong way around by press one or another key. There were 20 practice trials and 80 test trials ( 5 angles $\times 2$ orientations) in total. Accuracy and response time were recorded.

\section{STOP-SIGNALTASK}

A child-friendly stop-signal task was used. The go stimuli in this stop-signal task comprised of a strawberry and a peach $(150 \times 150$ px in size), and the stop trials consisted of an apple of the same size. 


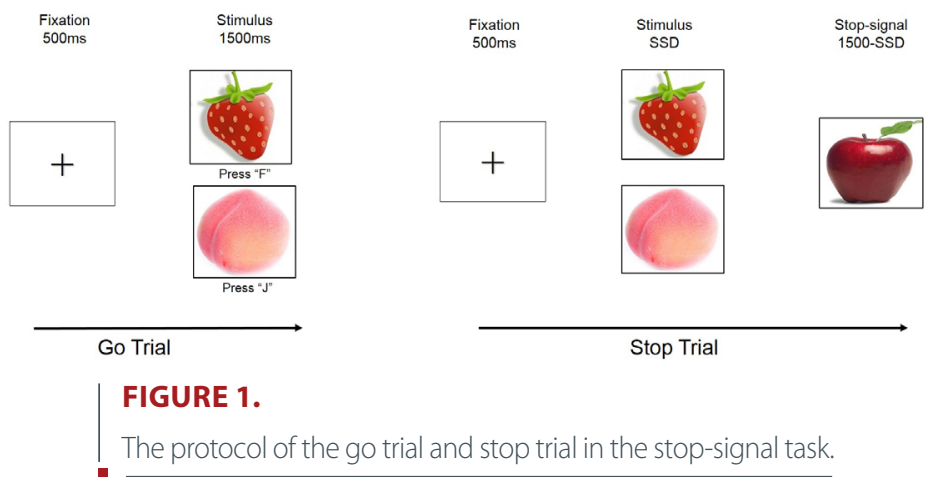

Participants were instructed to press $F$ when a strawberry appeared, and $J$ when a peach did (go-trials), but they had to inhibit their response when an apple appeared shortly after the presentation of the go-stimulus (stop trial). Each trial began with a fixation cross lasting for $500 \mathrm{~ms}$, followed by a go stimulus lasting for $1500 \mathrm{~ms}$ in the case of go trials. For stop trials, the stop-signal delays (SSD), the time between the go stimulus onset and stop-signal onset, were set to 100 $\mathrm{ms}, 200 \mathrm{~ms}, 300 \mathrm{~ms}$, and $400 \mathrm{~ms}$. The stop-signal was displayed for a maximum of $1500 \mathrm{~ms}$ (see Figure 1). There was one practice block (40 trials) and four test blocks in total. Each test block included 80 trials and $25 \%$ of the trials were stop-trials. The stop-trials were presented at random positions throughout each block and were counterbalanced among the four SSDs. For the dependent variable, we used the stopsignal response time (SSRT), which was calculated by subtracting the mean SSD from the $|\mathrm{n}|$ th RT (the integration method, Verbruggen et al., 2013).

\section{Data Analysis}

For each child in each task, mean RT and accuracy (percentage of correct responses) were calculated for each angle in the mental rotation tasks. To remove anticipatory and abnormally delayed responses, response times shorter than $250 \mathrm{~ms}$ and longer than 2.5 times the mean RT for each angle for each participant were excluded from analysis (Kosslyn et al., 1998).

To test the developmental change of motor imagery, we ran a set of mixed ANOVAs for accuracy score and RT of correct responses using age group (7-year-olds, 9-year-olds, and 11-year-olds) and gender (male and female) as between-subjects factors, and angle $\left(0^{\circ}, 45^{\circ}, 90\right.$ $\left.\circ, 135^{\circ}, 180^{\circ}\right)$ as the within-subjects factor.

As the slope of mental rotation tasks was considered to be a key measure of the mental rotation process (Badets et al., 2013; Shepard \& Cooper, 1982; Toussaint et al., 2013), we computed each participant's slope of the linear function between RTs and rotation angles for the two mental rotation tasks. Individual regression slopes were then analyzed using a 3 (age group: 7-year-olds, 9-year-olds, and 11-year-olds) $\times 2$ (gender: male and female) ANOVA.

For the stop-signal task, SSRT was computed and then analyzed by using a 3 (age: 7-year-olds, 9-year-olds, and 11-year-olds) $\times 2$ (gender: male and female) $\times 4$ (SSD: $100 \mathrm{~ms}, 200 \mathrm{~ms}, 300 \mathrm{~ms}, 400 \mathrm{~ms})$ repeatedmeasures ANOVA.
SPSS 24.0 was used to analyze the data. For all the ANOVAs, homogeneity and sphericity tests were conducted, and Greenhouse-Geisser correction was employed when necessary. The Bonferroni method was executed to conduct all the multiple comparisons, corrected alphas were provided in the Results section as well. The $p$ value we report in the Results section is corrected, which was compared with .05 directly.

To clarify whether participants employed the KMI, we ran pairedsamples $t$ tests to compare the overall RT and RTs for each rotation angle of the two mental rotation tasks in each age group.

Given our study aims to investigate the relationship between motor imagery and motor inhibition, Spearman's correlations between the efficiency of motor inhibition and the individual slope of the two mental rotation tasks was calculated within each age group (Pfister et al., 2013; Toussaint et al., 2013). The Fisher's $r$-to- $Z$ transformation was used to test the difference between the correlation coefficients obtained for the three age groups

\section{RESULTS}

\section{Hand Laterality Judgment Task}

For RTs, descriptive data for all angles and groups are provided in Table 1. The main effect of age was significant, $F(2,67)=4.59, p=.014, \eta_{\mathrm{p}}{ }^{2}=$ .12. The multiple comparisons (Bonferroni corrected $\alpha=.017$ ) showed that RTs for 7-year-olds were significantly longer than that for both 9 -year-olds $(t=2.59, p=.042, d=0.71)$ and 11-year-olds $(t=2.75, p=$ $.023, d=0.80)$. No significant difference was detected between 9 -yearolds and 11-year-olds $(t=0.26, p=1.000, d=0.10)$. A significant main effect of angle was observed, $F(4,268)=29.69, p<.001, \eta_{\mathrm{p}}{ }^{2}=.31$, suggesting that RT increased with rotation angles expanded(Bonferroni corrected $\alpha=.005)$. Multiple comparisons showed that RT at $0^{\circ}$ was significantly shorter than that at $90^{\circ}(t=3.97, p=.002, d=0.46), 135^{\circ}$ $(t=5.65, p<.001, d=0.64)$, and $180^{\circ}(t=8.17, p<.001, d=0.93)$, RT at $45^{\circ}$ was significantly shorter than that at $90^{\circ}(t=5.02, p<.001, d=$ $0.57), 135^{\circ}(t=6.30, p<.001, d=0.71)$, and $180^{\circ}(t=8.24, p<.001, d$ $=0.93)$, RT at $90^{\circ}$ was significantly shorter than that at $180^{\circ}(t=6.30, p$ $<.001, d=0.53)$, and that $\mathrm{RT}$ at $135^{\circ}$ was significantly shorter than that at $180^{\circ}(t=4.62, p=.045, d=0.36)$. No other significant differences were detected. The main effect of gender was not statistically significant, $F(1,67)=1.83, p=.179, \eta_{\mathrm{p}}{ }^{2}=.03$. None of the interaction effects 


\begin{tabular}{llllllll}
\hline TABLE 1. & \multicolumn{1}{l}{ 1. } \\
Comparison of Mean Response Time (ms) for the Hand Later- \\
ality Judgment Task and Alphanumeric Rotation Task
\end{tabular}

between angle and age, $F(8,268)=1.65, p=.11, \eta_{\mathrm{p}}{ }^{2}=.05$, between age and gender, $F(2,67)=1.06, p=.35, \eta_{\mathrm{p}}{ }^{2}=.03$, between angle and gender, $F(4,268)=0.56, p=.67, \eta_{\mathrm{p}}{ }^{2}=.01$, and between angle, age, and gender, $F(8,268)=0.75, p=.63, \eta_{\mathrm{p}}{ }^{2}=.02$, were detected (see Figure 2, Panel A).

For accuracy scores, the main effect of age was significant, $F(2,67)$ $=9.82, \mathrm{p}<.001, \eta_{\mathrm{p}}{ }^{2}=.23$, suggesting accuracy scores increased with age $(7$-year-olds $=70 \pm 3 \%$, 9-year-olds $=75 \pm 3 \%$, 11-year-olds $=90$ $\pm 3 \%$ ). Multiple comparisons (Bonferroni corrected $\alpha=.017$ ) showed that 11-year-olds performed significantly better than 7-year-olds $(t=$ 4.26, $p<.001, d=1.42)$ and 9-year-olds $(t=3.25, p=.006, d=1.01)$, but no significant difference was detected between 7 -year-olds and 9 -year-olds $(t=1.23, p=0.686, d=0.45)$. The main effect of angle was also significant, $F(4,268)=8.68, p<.001, \eta_{\mathrm{p}}{ }^{2}=.12$, showing that the accuracy scores significantly decreased with the angles $\left(0^{\circ}=82\right.$ $\pm 2 \%, 45^{\circ}=82 \pm 2 \%, 90^{\circ}=79 \pm 2 \%, 135^{\circ}=77 \pm 3 \%, 180^{\circ}=73$ $\pm 2 \%$ ). Pairwise comparisons (Bonferroni corrected $\alpha=.005$ ) showed that accuracy scores at $135^{\circ}$ were significantly lower than at $0^{\circ}(t=$ $2.95, p=.037, d=0.36$ ), accuracy scores at $180^{\circ}$ were significant lower than at $0^{\circ}(t=4.68, p<.001, d=0.56)$ and $45^{\circ}(t=4.53, p<.001, d$ $=0.56)$. No other differences were detected. The main effect of gender was not statistically significant, $F(1,67)=0.011, p=.916, \eta_{\mathrm{p}}{ }^{2}<.01$. None of the interaction effects between angle and age, $F(8,268)=0.62$, $p=.743, \eta_{\mathrm{p}}{ }^{2}=.02$, between age and gender, $F(2,67)=0.48, p=.619, \eta_{\mathrm{p}}{ }^{2}$ $=.03$, between angle and gender, $F(4,268)=1.50, p=.207, \eta_{\mathrm{p}}{ }^{2}=.02$, or between angle, age, and gender, $F(8,268)=1.34, p=.229, \eta_{\mathrm{p}}{ }^{2}=.04$, were significant (see Figure 3, Panel A).

An analysis of individual regression slopes revealed that the main effect of age was not statistically significant, $F(2,67)=2.99, p=.057$, $\eta_{\mathrm{p}}{ }^{2}=.08$, but the slope increased from 7-year-olds $\left(201 \mathrm{~ms} / 45^{\circ}\right)$ to 9-year-olds $\left(112 \mathrm{~ms} / 45^{\circ}\right)$ and 11-years-olds $\left(219 \mathrm{~ms} / 45^{\circ}\right)$, showing an increasing trend with age. No statistically significant main effect of gender was detected, $F(1,67)=0.88, p=.350, \eta_{\mathrm{p}}^{2}=.01$.

\section{Alphanumeric Rotation Task}

For RT, descriptive data for all angles and groups are provided in Table 1. The main effect of age was not statistically significant, $F(2,67)=1.97$, $p=.147, \eta_{\mathrm{p}}{ }^{2}=.06$. A significant main effect of angle was observed, $F(4$, 268) $=33.29, p<.001, \eta_{\mathrm{p}}{ }^{2}=.33$, suggesting that RTs increased with rotation angles. Pairwise comparisons (Bonferroni corrected $\alpha=.005$ ) showed that RTs at $0^{\circ}$ were significantly shorter than at $45^{\circ}(t=3.58$, $p=.006, d=0.42), 90^{\circ}(t=5.71, p<.001, d=0.67), 135^{\circ}(t=6.37$, $p<.001, d=0.76)$, and $180^{\circ}(t=9.23, p<.001, d=1.09)$, RTs at 45 ${ }^{\circ}$ were significantly shorter than at $135^{\circ}(t=3.91, p=.002, d=0.46)$ and $180^{\circ}(t=6.95, p<.001, d=0.82)$, RTs at $90^{\circ}$ were significantly shorter than at $180^{\circ}(t=5.66, p<.001, d=0.67)$, and that RTs at $135^{\circ}$ were significant shorter than at $180^{\circ}(t=3.92, p=.002, d=0.45)$. No other statistically significant differences were detected. The main effect of gender was not statistically significant, $F(1,67)=0.05, p=.826, \eta_{\mathrm{p}}{ }^{2}$ $=.001$. None of the interaction effects between angle and age, $F(8,268)$ $=0.76, p=.605, \eta_{\mathrm{p}}^{2}=.02$, between age and gender, $F(2,67)=0.48, p=$ $.619, \eta_{\mathrm{p}}{ }^{2}=.01$, between angle and gender, $F(4,268)=0.34, p=.808, \eta_{\mathrm{p}}{ }^{2}$ $=.005$, or between angle, age and gender, $F(8,268)=1.80, p=.098, \eta_{\mathrm{p}}{ }^{2}$ $=.05$, were significant (see Figure 2, Panel A).

For accuracy scores, the main effect of age was significant, $F(2,67)$ $=6.73, p=.002, \eta_{\mathrm{p}}^{2}=.17$, suggesting accuracy scores increased with age (7-year-olds $=73 \pm 3 \%$, 9-year-olds $=75 \pm 3 \%, 11$-year-olds $=88 \pm 3 \%)$. Specifically, 11-year-olds performed significantly better than 7-yearolds $(t=3.31, p=.004, d=1.04)$ and 9-year-olds $(t=3.02, p=.01, d=$ 0.87 ), but no significant difference was detected between 7 -year-olds
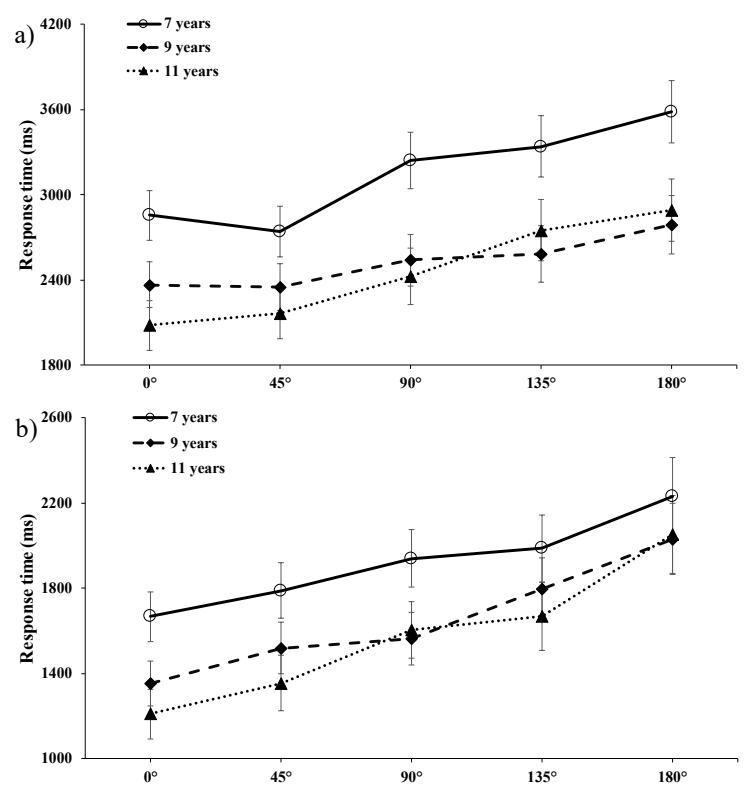

FIGURE 2.

Mean response time (ms) in the Hand Laterality Judgment Task (Panel A) and the Alphanumeric Rotation Task (Panel B) as a function of age $(7,9$, and 11$)$ and stimulus rotation angle $\left(0^{\circ}, 45\right.$ ${ }^{\circ}, 90^{\circ}, 135^{\circ}, 180^{\circ}$. Error bars indicate the SEM. 

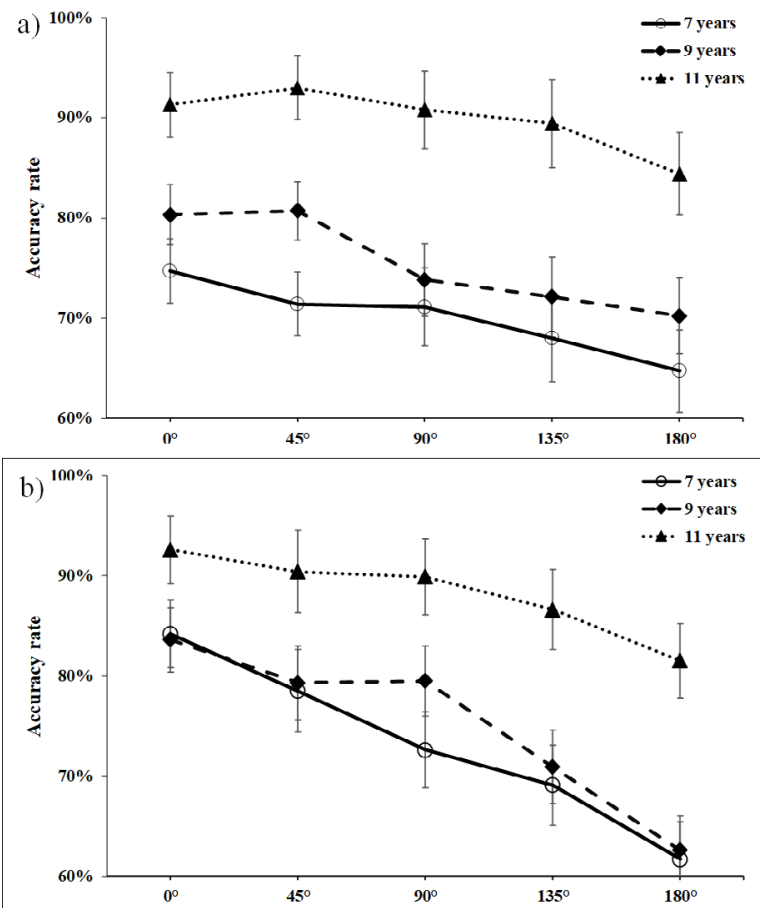

FIGURE 3.

Mean accuracy in the Hand Laterality Judgment Task (Panel A) and the Alphanumeric Rotation Task (Panel B) as a function of age $(7,9$, and 11$)$ and stimulus rotation angle $\left(0^{\circ}, 45^{\circ}, 90^{\circ}, 135\right.$ ${ }^{\circ}, 180^{\circ}$ ). Error bars indicate the SEM.

and 9-year-olds. The main effect of angle was also significant, $F(4,268)$ $=27.12, p<.001, \eta_{\mathrm{p}}{ }^{2}=.29$, showing that accuracy scores significantly decreased as the rotation angle increased $\left(0^{\circ}=87 \pm 2 \%, 45^{\circ}=83 \pm 2 \%\right.$, $\left.90^{\circ}=80 \pm 2 \%, 135^{\circ}=76 \pm 3 \%, 180^{\circ}=67 \pm 2 \%\right)$. Pairwise comparisons (Bonferroni corrected $\alpha=0.005$ ) showed that accuracy at $0^{\circ}$ was significantly higher than at $90^{\circ}(t=3.39, p=.013, d=0.39), 135^{\circ}(t=6.59$, $p<0.001, d=0.76)$, and $180^{\circ}(t=8.62, p<.001, d=1.02)$, accuracy at $45^{\circ}$ was significantly higher than at $135^{\circ}(t=4.00, p=.002, d=0.48)$ and $180^{\circ}(t=5.83, p<.001, d=0.72)$, accuracy at $90^{\circ}$ was significant higher than at $135^{\circ}(t=3.00, p=.032, d=0.37)$ and $180^{\circ}(t=5.71, p<$ $.001, d=0.69)$, and that accuracy at $135^{\circ}$ was significant higher at 180 ${ }^{\circ}(t=3.40, p=.013, d=0.41)$. No other differences were detected. The main effect of gender was not statistically significant, $F(1,67)=0.003, p$ $=.959, \eta_{\mathrm{p}}{ }^{2}<.01$. None of the interaction effects between angle and age, $F(8,268)=1.43, p=.195, \eta_{\mathrm{p}}{ }^{2}=.04$, between age and gender, $F(2,67)=$ $1.98, p=.146, \eta_{\mathrm{p}}{ }^{2}=.06$, between angle and gender, $F(4,268)=0.33, p$ $=.829, \eta_{\mathrm{p}}{ }^{2}=.01$, or among angle, age, and gender, $F(8,268)=1.03, p=$ $.410, \eta_{\mathrm{p}}{ }^{2}=.03$, were significant (see Figure 3, Panel B).

An analysis of individual regression slopes revealed that the main effect of age was not statistically significant, $F(2,67)=1.45, p=.242$, $\eta_{\mathrm{p}}^{2}=.04$, but the slope increased from 7 -year-olds $\left(127 \mathrm{~ms} / 45^{\circ}\right)$ to 9-year-olds $\left(157 \mathrm{~ms} / 45^{\circ}\right)$, and 11-years-olds $\left(201 \mathrm{~ms} / 45^{\circ}\right)$, showing an increasing trend with age. No statistically significant main effect of gender was detected, $F(1,67)=0.12, p=.732, \eta_{\mathrm{p}}{ }^{2}=.54$, and no significant interaction effect between gender and age was detected, $F(2,67)=$ $0.62, p=.539, \eta_{\mathrm{p}}^{2}=.02$.
A comparison of the overall RT and RTs for each angle in each task was conducted by a paired-samples $t$ test. The results showed that overall mean RT for the hand laterality judgment task was significantly longer than that for alphanumeric rotation task, $t(22)=5.63, p<.001, d$ $=1.17 ; t(26)=5.94, p<.001, d=1.14 ; t(22)=6.17, p<.001, d=1.29$. All the other comparisons were significant ( $p$ s $<.001$, see Table 1$)$.

\section{Stop-Signal Task}

Descriptive data of this task for all groups are provided in Table 2.

The main effect of age was significant, $F(2,67)=6.86, p=.002, \eta_{\mathrm{p}}{ }^{2}=$ .17. A significant difference was detected between SSRT for 7-year-olds and 9-year-olds ( $t=2.59, p=.035, d=0.68)$, as well as 7 -year-olds and 11 -year-olds $(t=3.61, p=.001, d=1.41)$. No significant differences were detected between SSRT for 9-year-olds and 11-year-olds ( $t=1.16$, $p=.249, d=0.33)$. A significant main effect of SSD was detected, $F(3$, 201 ) $=26.12, p<.001, \eta_{\mathrm{p}}^{2}=.28$. Pairwise comparisons (Bonferroni corrected $\alpha=0.008$ ) indicated that the SSRT at $100 \mathrm{~ms}$ SSD was significantly longer than at $200 \mathrm{~ms} \mathrm{SSD}(t=5.26, p<.001, d=0.62)$, at 300 $\operatorname{msSSD}(t=6.67, p<.001, d=0.80)$, and at $400 \mathrm{msSSD}(t=9.70, p<$ $.001, d=1.13)$. No other statistically significant effects were detected. No main effect of gender was detected, $F(1,67)=0.002, p=.960, \eta_{\mathrm{p}}{ }^{2}<$ .001 . The interaction effects between age and $\operatorname{SSD}, F(6,201)=0.69, p=$ $.637, \eta_{\mathrm{p}}{ }^{2}=.02$, the between gender and SSD, $F(3,201)=0.67, p=.555$, $\eta_{\mathrm{p}}^{2}=.01$, between age and gender, $F(2,67)=0.36, p=.703, \eta_{\mathrm{p}}^{2}=.01$, and between SSD, age, and gender, $F(6,201)=1.76, p=.119, \eta_{\mathrm{p}}{ }^{2}=0.05$, were not statistically significant (see Figure 4).

\section{Relationship Between Internal Motor Imagery and Motor Inhibition}

There was no significant Spearman's correlation between motor inhibition and the slopes of the two rotation tasks for all the groups (see Table 3).

Moreover, the Fisher's $r$-to- $Z$ transformation for the hand laterality judgment task showed that a significant difference existed between 7 - and 9-year-olds $(Z=2.46, p<.001, q=0.71)$, and no difference was detected between 7 - and 11-year-olds $(Z=1.21, p=.110, q=0.32)$, and 9 - and 11-year-olds $(Z=-1.19, p=.124, q=0.38)$. These results suggest that the difference between 7- and 9-year-olds in KMI might be due to the capacity to engage in motor inhibition.

For the alphanumeric rotation task, the Fisher's $r$-to- $Z$ transformation showed no significant difference between 7 - and 9-year-olds $(Z=$ $0.42, p=.332, q=0.21), 7$ - and 11- year-olds $(Z=0.5, p=.314, q=0.27)$, or 9- and 11-year-olds $(Z=-1.09, p=.138, q=0.49)$. These results suggest that better motor inhibition was associated with the higher slope values in the three age groups considered in the present study.

\section{DISCUSSION}

The main objective of the present study was to investigate the link between internal motor imagery ability and motor inhibition in school-aged children and how this link differs across age. First, the mean accuracy of both mental rotation tasks across all age groups was 


\begin{tabular}{|c|c|c|c|c|c|}
\hline Group & $\begin{array}{l}\text { SSD } \\
(\mathrm{ms})\end{array}$ & $\begin{array}{l}\text { Go } \\
\text { ACC }\end{array}$ & $\begin{array}{l}\mathrm{M} \text { of Go } \\
\text { RT (ms) }\end{array}$ & SSRT (ms) & $\begin{array}{c}\text { Probability of } \\
\text { responding } \\
\text { on Stop trials }\end{array}$ \\
\hline \multirow{5}{*}{$\begin{array}{l}\text { 7-year- } \\
\text { olds }\end{array}$} & 100 & \multirow{5}{*}{$\begin{array}{c}0.88 \\
(0.11)\end{array}$} & \multirow{5}{*}{$\begin{array}{c}836.05 \\
(120.45)\end{array}$} & 424.33 (108.08) & $0.08(0.14)$ \\
\hline & 200 & & & 358.46 (131.44) & $0.11(0.15)$ \\
\hline & 300 & & & $326.03(81.94)$ & $0.18(0.18)$ \\
\hline & 400 & & & $306.59(58.70)$ & $0.34(0.17)$ \\
\hline & Overall & & & $353.85(43.32)$ & $0.16(0.13)$ \\
\hline \multirow{5}{*}{$\begin{array}{l}\text { 9-year- } \\
\text { olds }\end{array}$} & 100 & \multirow{5}{*}{$\begin{array}{c}0.90 \\
(0.11)\end{array}$} & \multirow{5}{*}{$\begin{array}{c}763.81 \\
(122.71)\end{array}$} & $379.72(87.30)$ & $0.06(0.14)$ \\
\hline & 200 & & & $289.91(127.25)$ & $0.10(0.18)$ \\
\hline & 300 & & & $298.20(81.29)$ & $0.22(0.20)$ \\
\hline & 400 & & & $295.23(73.13)$ & $0.41(0.22)$ \\
\hline & Overall & & & $315.76(66.13)$ & $0.17(0.11)$ \\
\hline \multirow{5}{*}{$\begin{array}{l}11 \text {-year- } \\
\text { olds }\end{array}$} & 100 & \multirow{5}{*}{$\begin{array}{c}0.96 \\
(0.05)\end{array}$} & \multirow{5}{*}{$\begin{array}{c}771.29 \\
(103.90)\end{array}$} & 377.78 (54.35) & $0.02(0.67)$ \\
\hline & 200 & & & $283.77(60.96)$ & $0.02(0.49)$ \\
\hline & 300 & & & 268.44 (61.47) & $0.13(0.16)$ \\
\hline & 400 & & & $263.76(58.71)$ & $0.30(0.20)$ \\
\hline & Overall & & & 298.44 (35.04) & $0.11(0.10)$ \\
\hline
\end{tabular}

Note. SSD = stop-signal delay; $\mathrm{ACC}=$ accuracy; SSRT = stop-signal response time. $S D$ s are given in brackets.

above $65 \%$. This indicated that children can identify the direction of depicted body or nonbody stimuli accurately, and thus have the ability to solve the task (e.g., Frick et al., 2013; Spruijt et al., 2015). In addition, the RT for both the hand laterality judgment task (a task associated with KMI) and the alphanumeric rotation task (assessing VMI) of all age groups showed a typical pattern, that is, our results replicated the positive linear relation between RT and angular disparity. This finding was in line with other studies employing the same tasks and the same stimulus orientation in children at school age (e.g., Caeyenberghs et al., 2009; de Lange et al., 2006; Funk et al., 2005; Spruijt et al., 2015; ter Horst et al., 2010; Williams et al., 2006). Moreover, a comparison of the RT for the hand laterality judgment task and the alphanumeric rotation task across angles showed that the former was significantly longer than the latter. Since the time taken to perform a mental task is an index of the cognitive processes underlying that mental task, a higher time requirement in the hand laterality judgment task might suggest the use of a KMI strategy (Jeannerod, 1997; McAvinue \& Robertson, 2008).

Regarding the age-related differences, we found that the performance in both rotation tasks was better in the older age group than the younger age group. This provided further evidence that internal imagery develops during this five-year period (Caeyenberghs et al., 2009; Smits-Engelsman \& Wilson, 2013; Spruijt et al., 2015; Spruijt et al., 2017). Moreover, our results are in line with the developmental trend reported in external motor imagery ability research (Gabbard et al., 2012; Hoyek et al., 2009). Although researches demonstrated that internal imagery develops before external imagery, whether children in our study had achieved a mature response pattern of internal motor imagery needs further elucidation (Estes, 1998; Toussaint et al., 2013)

Notably, our results did not show significant gender differences. This is in line with several studies conducted in typically developing children which reported no gender differences regarding the general ability to form mental images (Munroe-Chandler, Hall, Fishburne, \& Hall, 2007; Munroe-Chandler, Hall, Fishburne, \& Strachan, 2007). Research suggests that children's mental rotation ability is affected by their academic programs and spatial activity experiences (e.g., Habacha et al., 2014; Logie et al., 2011; Pietsch \& Jansen, 2012). Our population consisted of typically developing children from predominantly privileged backgrounds, where girls and boys are receiving the same education, which might lead to their comparable performance across tasks. But in another study, Hoyek et al. (2009) recruited 8- to 12-year-olds to imagine performing a sequence of different motor tasks. They found that boys outperformed girls in imagery performance, and speculated that boys might be able to form more accurate mental images in realtime due to their higher visuo-spatial ability. Whether or not children's imagery performance is influenced by their spatial abilities is hard to determine in our data

Motor inhibition ability can be reflected through the SSRT in the stop-signal task, specifically, a short SSRT suggests a high efficiency in motor inhibition. The SSRT in the present study decreased when SSD increased. This was consistent with previous findings (Verbruggen et al., 2013). Meanwhile, SSRT decreased from 7-year-olds to 11-yearolds, suggesting that there is an improvement of motor inhibition ability in school-aged children, and confirming similar findings from studies using the stop-signal task or other tasks (Chevalier et al., 2012; Davidson et al., 2006). However, a significant SSRT difference was only detected between 7-year-olds and 9-year-olds and 7-year-olds and 11 -year-olds but not between 9-year-olds and 11-year-olds. A possible reason might be that inhibitory control develops rapidly during the first two years of formal schooling, and then demonstrates a slower increase rate (Sadeghi et al., 2020). Another possible explanation could be that the same task may not be developmentally appropriate for all ages (Petersen et al., 2016). Alternative tasks, such as the go/no-go task, flanker task, circle-tracing task, and so forth would allow us to accommodate developmental changes in the manifestation of motor inhibition (Sadeghi et al., 2020).

Regarding the relationship between internal motor imagery and motor inhibition, no correlation between performance of hand laterality judgment task and stop-signal task was found. Our results

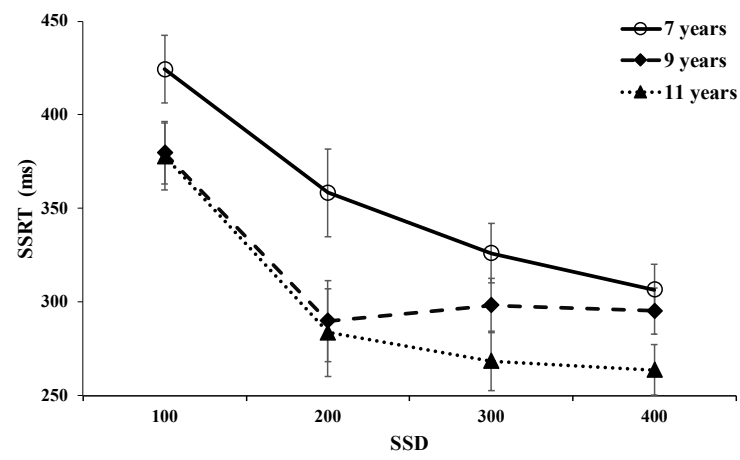

FIGURE 4.

The stop-signal response time (SSRT) in the stop-signal task as a function of age (7, 9, and 11) and stop-signal delay (SD, 100, 200, 300, and $400 \mathrm{~ms})$. Error bars indicate the SEM. 


TABLE 3.
Spearman's Correlation Between Inhibition Efficiency (SSRT)
and the Slopes of the Hand Laterality Judgment Task and
Alphanumeric Rotation Task
\begin{tabular}{lll} 
Task by age groups & Correlation \\
coefficients & $p$ \\
\hline Hand Laterality Judgment Task & & \\
7-year-olds & 0.39 & .06 \\
9-year-olds & -0.29 & .15 \\
11-year-olds & 0.09 & .67 \\
\hline Alphanumeric Rotation Task & & \\
\hline 7-year-olds & -0.15 & .49 \\
9-year-olds & -0.35 & .07 \\
11-year-olds & 0.12 & .59 \\
\hline
\end{tabular}

suggest that both children's abilities of internal motor imagery and motor inhibition refine as they develop, but whether motor inhibition is involved in internal KMI needs further investigation. Fisher's $r$-to- $Z$ transformation was further used to test the difference between the correlation coefficients obtained for three age groups. We found a significant difference between 7- and 9-year-olds in the relation between the hand laterality judgment task performance and the stop signal task performance, that is, the relation between KMI and motor inhibition decreases from 7-year-olds to 9-year-olds. This suggest that the involvement of motor inhibition in internal motor imagery might change with age. However, we failed to find any other significant age differences regarding the relation between the alphanumeric rotation task performance and the stop signal task performance. Our results are in line with previous findings suggesting that the hand laterality judgment task is more strongly associated with cognitive control of action (Caeyenberghs et al., 2009; Graybiel, 2000). As the RTs for the hand laterality judgment task are longer than that for the alphanumeric rotation task, our results suggest that children were relying on different strategies to perform the two tasks, which could be a possible reason for the dissociation of the motor inhibition involvement in KMI and VMI (McAvinue \& Robertson, 2008). But whether the KMI and internal VMI have different developmental trajectories since childhood needs further investigation (Casey et al., 2005; Guillot et al., 2009; Jiang et al., 2015).

\section{Limitations}

Several limitations of this study should be noted. First, an increased $\mathrm{RT}$ and/or decreased response accuracy when mentally rotating lateral (rotation angles between $180^{\circ}$ and $360^{\circ}$ ) compared to medial (rotation angles between $0^{\circ}$ and $180^{\circ}$ ) hand stimuli, as well as an increased $\mathrm{RT}$ and/or decreased response accuracy when the participants' hand orientation is incongruent with the orientation of the depicted hand would both help us capture children's employment of KMI (de Lange et al., 2006; Shenton et al., 2004; ter Horst et al., 2010). Moreover, KMI is rated as more difficult to mobilize than other types of imagery. Even if children have received specific instructions and understood the difference between KMI and VMI, it is still difficult to dissociate KMI and VMI (Guillot et al., 2009). Using both physiological measures from the autonomic neural system and the motor imagery questionnaire, the assessment quality of motor imagery would most likely to be improved (Guillot et al., 2009; Martini et al., 2016).

Second, we observed relatively small effects in the correlation analysis. A possible reason might be that typically developing children did not provide sufficient information about the relation between motor imagery and motor inhibition. Future studies should consider recruiting children with developmental coordination disorders and cerebral palsy, showing deficiency in both rapid online movement control and motor imagery, to further reveal the involvement of motor inhibition in the process of motor imagery (Adams et al., 2014; Hyde \& Wilson, 2011a, 2011b; Wilson et al., 2013; Wolpert, 1997).

Another caveat that might impede the generalization of our results is the cross-sectional study design, which could not demonstrate whether there is any causal effect between internal motor imagery and motor inhibition and show how the associations in the present study may change over time. Overall, future studies with a longitudinal design, more representative samples, and a more comprehensive measurement of motor imagery would allow us to explore the cognitive processes involved between internal motor imagery and motor inhibition.

\section{CONCLUSIONS}

To conclude, our work provides further evidence for the development of internal motor imagery and motor inhibition abilities, illustrating progressive development characteristics in school aged children. Specifically, our results suggest that typically developing children at 7 years old are able to use internal motor imagery. Moreover, the difference of the relation between internal motor imagery and motor inhibition between 7- and 9-year-olds suggests this age range is be a sensitive window to explore the involvement of motor inhibition in internal motor imagery processes. Our work provides support for potential application of incorporating internal motor imagery training in rehabilitation protocols in children.

\section{ACKNOWLEDGEMENTS}

The authors declare that they have no actual or potential financial, personal or professional conflicts of interest.

This study was supported by the National Natural Science Foundation of China (No.31100753), National Key Technologies R \&DProgram (No.2012BAI36B02), the Natural Sciences Foundation of Zhejiang Province (No.LY16C090002, LY17H090002), the Social Sciences Foundation of Zhejiang Province (No.11ZJQN033YB) and the Fundamental Research Funds for the Central Universities (No.2020QNA3005).

We would like to express our gratitude to all the participants in the study.

\section{REFERENCES}

Adams, I. L., Lust, J. M., Wilson, P. H., \& Steenbergen, B. (2014). Compromised motor control in children with DCD: A deficit in the internal model - a systematic review. Neuroscience \& Biobehavioral 
Reviews, 47, 225-244. doi: 10.1016/j.neubiorev.2014.08.011 سلس Angelini, M., Calbi, M., Ferrari, A., Sbrisciafioretti, B., Franca, M., Gallese, V., \& Umilta, M. A. (2015). Motor inhibition during overt and covert actions: an electrical neuroimaging study. PLoS One, 10, e0126800. doi: 10.1371/journal.pone.0126800 الس

Badets, A., Koch, I., \& Toussaint, L. (2013). Role of an ideomotor mechanism in number processing. Experimental Psychology, 60, 34-43. doi: 10.1027/1618-3169/a000171 البلسلس

Batula, A. M., Mark, J. A., Kim, Y. E., \& Ayaz, H. (2017). Comparison of brain activation during motor imagery and motor movement using fNIRS. Computational Intelligence and Neuroscience, 2017, 5491296. doi: 10.1155/2017/5491296 السلس

Caeyenberghs, K., Tsoupas, J., Wilson, P. H., \& Smits-Engelsman, B. C. M. (2009). Motor imagery development in primary school children. Developmental Neuropsychology, 34, 103-121. doi: 10.1080/87565640802499183 الملسلس

Callow, N., \& Waters, A. (2005). The effect of kinesthetic imagery on the sport confidence of flat-race horse jockeys. Psychology of Sport \& Exercise, 6, 443-459. doi: 10.1016/j.psychsport.2004.08.001 الملسلس

Cameron, B. D., Enns, J. T., Franks, I. M., \& Chua, R. (2009). The hand's automatic pilot can update visual information while the eye is in motion. Experimental Brain Research, 195, 445-454. doi: 10.1007/ s00221-009-1812-7

Carlson, S. M., Mandell, D. J., \& Williams, L. (2004). Executive function and theory of mind: stability and prediction from ages 2 to 3. Developmental Psychology, 40, 1105-1122. doi: 10.1037/00121649.40.6.1105 السلسلس

Casey, B. J., Tottenham, N., Liston, C., \& Durston, S. (2005). Imaging the developing brain: what have we learned about cognitive development? Trends in Cognitive Sciences, 9, 104-110. doi: 10.1016/j. tics.2005.01.011 الس

Chevalier, N., Sheffield, T. D., Nelson, J. M., Clark, C. A. C., Wiebe, S. A., \& Espy, K. A. (2012). Underpinnings of the costs of flexibility in preschool children: The roles of inhibition and working memory. Developmental Neuropsychology, 37, 99-118. doi: 10.1080/87565641.2011.632458 المالسلس

Conson, M., Mazzarella, E., \& Trojano, L. (2013). Developmental changes of the biomechanical effect in motor imagery. Experimental

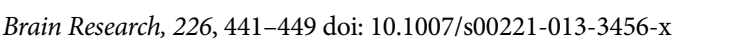

Davidson, M. C., Amso, D., Anderson, L. C., \& Diamond, A. (2006). Development of cognitive control and executive functions from 4 to 13 years: evidence from manipulations of memory, inhibition, and task switching. Neuropsychologia, 44, 2037-2078. doi: 10.1016/j. neuropsychologia.2006.02.006 الهالسلسلس

de Lange, F. P., Helmich, R. C., \& Toni, I. (2006). Posture influences motor imagery: An fMRI study. NeuroImage, 33, 609-617. doi: 10.1016/j.neuroimage.2006.07.017 المالسلس

de Lange, F. P., Roelofs, K., \& Toni, I. (2008). Motor imagery: A window into the mechanisms and alterations of the motor system. Cortex, 44, 494-506. doi: 10.1016/j.cortex.2007.09.002 السلسلسلس

Dutra, I. C., Waller, D. A., \& Wessel, J. R. (2018). Perceptual surprise improves action stopping by non selectively suppressing motor ac- tivity via a neural mechanism for motor inhibition. The Journal of Neuroscience: The Official Journal of the Society for Neuroscience, 38, 1482-1492. doi: 10.1523/JNEUROSCI.3091-17.2017 الس السلس

Elliott, D., Helsen, W. F., \& Chua, R. (2001). A century later: Woodworth's (1899) two-component model of goal-directed aiming. Psychological Bulletin, 127, 342-357. doi: 10.1037/00332909.127.3.342 المالس

Eaves, D. L., Riach, M., Holmes, P. S., \& Wright, D. J. (2016). Motor imagery during action observation: A brief review of evidence, theory and future research opportunities. Frontiers in Neuroscience, 10, 514. doi: 10.3389/fnins.2016.00514 السلسلس

Estes, D. (1998). Young children's awareness of their mental activity: The case of mental rotation. Child Development, 69, 1345-1360. doi:

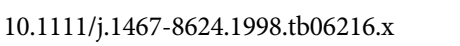

Farah, M. J. (1984). The neurological basis of mental imagery: A componential analysis. Cognition, 18, 245-272. doi: 10.1016/0010-

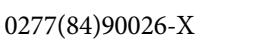

Frick, A., Hansen, M., \& Newcombe, N. S. (2013). Development of mental rotation in 3- to 5-year-old children. Cognitive Development, 28, 386-399. doi: 10.1016/j.cogdev.2013.06.002 المالسلس

Funk, M., Brugger, P., \& Wilkening, F. (2005). Motor processes in children's imagery: The case of mental rotation of hands. Developmental Science, 8, 402-408. doi: 10.1111/j.1467-7687.2005.00428.x المالسلس

Gabbard, C., Caçola, P., \& Bobbio, T. (2012). The ability to mentally represent action is associated with low motor ability in children: A preliminary investigation. Child: Care, Health and Development, 38, 390-393. doi: 10.1111/j.1365-2214.2011.01257.x المالسلس

Glover, S. (2004). Separate visual representations in the planning and control of action. Behavioral and Brain Sciences, 27, 3-24. المالسلسلس

Glover, S., \& Baran, M. (2017). The motor-cognitive model of motor imagery: Evidence from timing errors in simulated reaching and grasping. Journal of Experimental Psychology: Human Perception and Performance, 43, 1359-1375. doi: 10.1037/xhp0000389 المالسلسلاس

Glover, S., Bibby, E., \& Tuomi, E. (2020). Executive functions in motor imagery: support for the motor-cognitive model over the functional equivalence model. Experimental Brain Research, 238, 931-944. doi: 10.1007/s00221-020-05756-4 المسلس

Guillot, A., Collet, C., Nguyen, V. A., Malouin, F., Richards, C., \& Doyon, J. (2009). Brain activity during visual versus kinesthetic imagery: An fMRI study. Human Brain Mapping, 30, 2157-2172. doi: 10.1002/hbm.20658 الس

Guillot, A., Di Rienzo, F., Maclntyre, T., Moran, A., \& Collet, C. (2012). Imagining is not doing but involves specific motor commands: Areview of experimental data related to motor inhibition. Frontiers in Human Neuroscience, 6, 247. doi: 10.3389/fnhum.2012.00247 |س山س Graybiel, A. (2000). The basal ganglia. Current Biology, 10, R509-R511. السلسلس Habacha, H., Molinaro, C., \& Dosseville, F. (2014). Effects of gender, imagery ability and sports practice on the performance of a mental rotation task. American Journal of Psychology, 127, 313-323. doi: 10.5406/amerjpsyc.127.3.0313 السلسلسلس

Hall, C. R. (2001). Imagery in sport and exercise. In R. N. Singer, H. A. Hausenblas, \& C. M. Janelle (Eds.), The handbook of sport psychol- 
ogy (2nd ed., pp. 529-549). John Wiley \& Sons Inc.

Hardwick, R. M., Caspers, S., Eickhoff, S. B., Swinnen, S. P. (2018). Neural correlates of action: Comparing meta-analyses of imagery, observation, and execution. Neuroscience and Biobehavioral Review, 94, 31-44. doi: 10.1016/j.neubiorev.2018.08.003 السلسلس

Hétu S., Grégoire M., Saimpont A., Coll M.-P., Eugčne F., Michon P. E., \& Jackson P. L. (2013). The neural network of motor imagery: An ALE meta-analysis. Neuroscience and Biobehavioral Reviews, 37, 930-949. doi: 10.1016/j.neubiorev.2013.03.017 المسلس

Hohlefeld, F. U., Nikulin, V. V., \& Curio, G. (2011). Visual stimuli evoke rapid activation $(120 \mathrm{~ms})$ of sensorimotor cortex for overt but not for covert movements. Brain Research, 1368, 185-195. doi: 10.1016/j.brainres.2010.10.035 السلسلس

Hoyek, N., Champely, S., Collet, C., Fargier, P., \& Guillot, A. (2009). Age and gender-related differences in the temporal congruence development between motor imagery and motor performance. Learning and Individual Differences, 19, 555-560. doi: 10.1016/j. lindif.2009.07.003

Hyde, C., \& Wilson, P. H. (2011a). Dissecting online control in Developmental Coordination Disorder: A kinematic analysis of double-step reaching. Brain and Cognition, 75, 232-241. doi: 10.1016/j.bandc.2010.12.004 سلس

Hyde, C., \& Wilson, P. H. (2011b). Online motor control in children with developmental coordination disorder: Chronometric analysis of double-step reaching performance. Child: Care Health and Development, 37, 111-122. doi: 10.1111/j.1365-2214.2010.01131.x المالسلس

Ikeda, Y., Okuzumi, H., \& Kokubun, M. (2014). Age-related trends of inhibitory control in Stroop-like big-small task in 3 to 12-yearold children and young adults. Frontiers in Psychology, 5, 227. doi: 10.3389/fpsyg.2014.00227 سلس

Jeannerod, M. (1994). The representing brain: neural correlates of motor intention and imagery. Behavioural and Brain Sciences, 17 , 187-245. एلس

Jeannerod, M., (1997). The cognitive neuroscience of action. Blackwell. Jeannerod, M. (2001). Neural simulation of action: A unifying mechanism for motor cognition. NeuroImage, 14, s103-s109. doi: 10.1006/ nimg.2001.0832

Jiang, D., Edwards, M. G., Mullins, P., \& Callow, N. (2015). The neural substrates for the different modalities of movement imagery. Brain and Cognition, 97, 22-31. doi: 10.1016/j.bandc.2015.04.005 السلسلس

Johnstone, S. J., Dimoska, A., Smith, J. L., Barry, R. J., Pleffer, C. B., Chiswick, D., \& Clarke, A. R. (2007). The development of stopsignal and Go/Nogo response inhibition in children aged 7-12 years: Performance and event-related potential indices. International Journal of Psychophysiology, 63, 25-38. doi: 10.1016/j.ijpsycho.2006.07.001

Jongbloed-Pereboom, M., Nijhuis-van der Sanden, M. W., Saraberschiphorst, N., Craje, C., \& Steenbergen, B. (2013). Anticipatory action planning increases from 3 to 10 years of age in typically developing children. Journal of Experimental Child Psychology, 114, 295-305. doi: 10.1016/j.jecp.2012.08.008 المالسلس

Khng, K. H., Lee, K. (2014). The relationship between stroop and stop- signal measures of iInhibition in adolescents: Influences from variations in context and measure estimation. PLoS One, 9, e101356. doi: 10.1371/journal.pone.0101356 الف الس

Kim, J. H., Sho, Y. S., Park, J. S., \& Kim, W. J., (2017). Effect of motor imagery training and electromyogram-triggered neuromuscular electrical stimulation on lower extremity function in stroke patients: A pilot trial. The Journal of Physical Therapy Science, 29, 1931-1933. doi: 10.1589/jpts.29.1931 الم

Kosslyn, S. M., Digirolamo, G. J., Thompson, W. L., Alpert, N. M. (1998). Mental rotation of objects versus hands: Neural mechanisms revealed by positron emission tomography. Psychophysiology, 35, 151-161. doi: 10.1111/1469-8986.3520151 एلس

Logan, G. D., \& Cowan, W. B. (1984). On the ability to inhibit thought and action: A theory of an act of control. Psychological Review, 91, 295-327. doi: 10.1037/0033-295X.91.3.295 المالسلس

Logie, R. H., Pernet, C. R., Buonocore, A., \& Sala, S. D. (2011). Low and high imagers activate networks differentially in mental rotation. Neuropsychologia, 49, 3071-3077. doi: 10.1016/j.neuropsychologia.2011.07.011 سلس

McAvinue, L. P. \& Robertson, I. H. (2008). Measuring motor imagery ability: A review. European Journal of Cognitive Psychology, 20, 232-251. doi: 10.1080/09541440701394624 الس

Martini, R., Carter, M. J., Yoxon, E., Cumming, J., \& Ste-Marie, D. M. (2016). Development and validation of the Movement Imagery Questionnaire for Children (MIQ-C). Psychology of Sport and Exercise, 20, 190-201. doi: 10.1016/j.psychsport.2015.08.008 المالسلسل|

Michelon, P., Vettel, J. M, \& Zacks, J. M. (2006). Lateral somatotopic organization during imagined and prepared movements. Journal of Neurophysiology, 95, 811-822. doi: 10.1152/jn.00488.2005 الملسلسلس

Moffitt, T. E., Arseneault, L., Belsky, D. W., Dickson, N., Hancox, R. J., Harrington, H., ... \& Caspi, A. (2011). A gradient of childhood selfcontrol predicts health, wealth, and public safety. Proceedings of the National Academy of Sciences of the United States of America, 108, 2693-2698. doi: 10.1073/pnas.1010076108 السلس

Moran, A., Guillot, A., Macintyre, T., \& Collet, C. (2012). Re-imagining motor imagery: building bridges between cognitive neuroscience and sport psychology. British Journal of Psychology, 103, 224-247. doi: 10.1111/j.2044-8295.2011.02068.x المسلس

Munroe-Chandler, K. J., Hall, C. R., Fishburne, G. J., \& Hall, N. (2007). The content of imagery use in youth sport. International Journal of Sport and Exercise Psychology, 2, 160-176. doi: 10.1080/1612197X.2007.9671817 السلسلس

Munroe-Chandler, K. J., Hall, C. R., Fishburne, G. J., \& Strachan, L. (2007). Where, when and why young athletes use imagery: An examination of developmental differences. Physical Education, Recreation and Dance, 78, 103-116. doi: 10.1080/02701367.2007.10599408 السلسلس

Munzert J., Lorey B., \& Zentgraf K. (2009). Cognitive motor processes: the role of motor imagery in the study of motor representations. Brain Research Review, 60, 306-326. doi: 10.1016/j.brainresrev.2008.12.024 المالسلسلس

Osuagwu, B. A., \& Vuckovic, A. (2014). Similarities between explicit and implicit motor imagery in mental rotation of hands: An EEG 
study. Neuropsychologia, 65, 197-210. doi: 10.1016/j.neuropsychologia.2014.10.029 السلس

Parsons, L. M. (1994). Temporal and kinematic properties of motor behavior reflected in mentally simulated action. Journal of Experimental Psychology: Human Perception and Performance, 20,

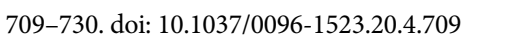

Petersen, I. T., Hoyniak, C. P., McQuillan, M. E., Bates, J. E., \& Staples, A. D. (2016). Measuring the development of inhibitory control: The challenge of heterotypic continuity. Developmental Review, 40, 25-71. doi: 10.1016/j.dr.2016.02.001 الس السلسلس

Pfister, R., Schwarz, K., Carson, R., \& Jancyzk, M. (2013). Easy methods for extracting individual regression slopes: Comparing spss, $\mathrm{R}$ and Excel. Tutorials in Quantitative Methods for Psychology, 9,

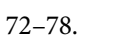

Pietsch, S., \& Jansen, P. (2012). The relationship between coordination skill and mental rRotation ability. In: C. Stachniss, K. Schill, \& D. Uttal (Eds.), SSpatial cognition 2012: Spatial cognition VIII. Lecture Notes in Computer Science, vol. 7463 (pp. 173-181). Springer.

Robin, N., Coudevylle, G. R., Guillot, A., \& Toussaint, L. (2020). French translation and validation of the Movement Imagery Questionnairethird version (MIQ-3f). Movement and Sport Science, 108, 23-31. doi: 10.1051/sm/2019035 السلسلسلس

Sadeghi, S., Shalani, B., Nejati, V. (2020). Sex and age-related differences in inhibitory control in typically developing children. Early Child

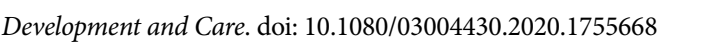

Seiler, B. D., Monsma, E. V., \& Newman-Norlund, R. D. (2015): Biological evidence of imagery abilities: Intraindividual differences. Journal of Sports and Exercise Psychology, 37, 421-435 doi: 10.1123/

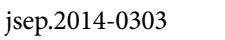

Shenton, J. T., Schwoebel, J., \& Coslett, H. B. (2004). Mental motor imagery and the body schema: Evidence for proprioceptive dominance. Neuroscience Letters, 370, 19-24. doi: 10.1016/j.neulet.2004.07.053 السلسلس

Shepard, R. N., \& Cooper, L. A. (1982). Mental images and their transformations. MIT Press.

Shepard, R. N., \& Metzler, J. (1971, February). Mental rotation of three-dimensional objects. Science, 171, 701-703. doi: 10.1126/science.171.3972.701 سلس

Šimleša, S., \& Cepanec, M. (2015). Development of executive functions during childhood. In Wright James (Ed.), International Encyclopedia of the Social \& Behavioral Sciences (2nd ed., pp. 489-496). Elsevier.

Smits-Engelsman, B. C. M., \& Wilson, P. H. (2013). Age-related changes in motor imagery from early childhood to adulthood: Probing the internal representation of speed-accuracy trade-offs. Human Movement Science. 32, 1151-1162. doi: 10.1016/j.humov.2012.06.006 سلس

Souto, D. O., Cruz, T., Coutinho, K., Julio-Costa, A., Fontes, P., \& Haase, V. G. (2020). Effect of motor imagery combined with physical practice on upper limb rehabilitation in children with hemiplegic cerebral palsy. NeuroRehabilitation, 46, 53-63. doi: 10.3233/NRE192931 |لس

Spruijt, S., Jongsma, M. L., Der Kamp, J. V., \& Steenbergen, B. (2017).
Examining developmental changes in children's motor imagery: A longitudinal study. Advances in Cognitive Psychology, 13, 257-266. doi: 10.5709/acp-0226-y السلسلس

Spruijt, S., van der Kamp, J., \& Steenbergen, B. (2015). Current insights in the development of children's motor imagery ability. Frontiers in Psychology, 6, 787. doi: 10.3389/fpsyg.2015.00787 السلسلس

ter Horst, A. C., van Lier, R., \& Steenbergen, B. (2010). Mental rotation task of hands: differential influence number of rotational axes. Experimental Brain Research, 203, 347-354. doi: 10.1007/s00221010-2235-1 الم

Tiego, J., Testa, R., Bellgrove, M. A., Pantelis, C., \& Whittle, S. (2018). A hierarchical model of inhibitory control. Frontiers in Psychology, 9, 1339. doi 10.3389/fpsyg.2018.01339 السلسلس

Tomasino, B., \& Gremese, M. (2016). Effects of stimulus type and strategy on mental rotation network: An activation likelihood estimation meta-analysis. Frontiers in Human Neuroscience, 9, 693. doi:

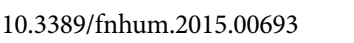

Toussaint, L., Tahej, P., Thibaut, J., Possamai, C., \& Badets, A. (2013). On the link between action planning and motor imagery: A developmental study. Experimental Brain Research, 231, 331-339. doi:

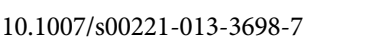

Verbruggen, F., Chambers, C. D., \& Logan, G. D. (2013). Fictitious inhibitory differences: How skewness and slowing distort the estimation of stopping latencies. Psychological Science, 24, 352-362. doi:

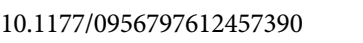

Verbruggen, F., \& Logan, G. D. (2008). Automatic and controlled response inhibition: associative learning in the go/no-go and stopsignal paradigms. Journal of Experimental Psychology. General, 137, 649-672. doi: 10.1037/a0013170 المالسلسلـ

Vry, M. S., Saur, D. Rijntjes, M., Umarova, R., Kellmeyer, P., Schnell, $S$... (2012). Ventral and dorsal fiber systems for imagined and executed movement. Experimental Brain Research, 219, 203-216 doi: 10.1007/s00221-012-3079-7 الهالسلس الس

Williams, S., Cumming, J., Ntoumanis, N., Nordin-Bates, S., Ramsey, R., \& Hall, C. (2012). Further validation and development of the movement imagery questionnaire. Journal of Sport \& Exercise Psychology, 34, 621-646. doi: 10.1123/jsep.34.5.621 السلسلس

Williams, J., Thomas, P., Maruff, P., Butson, M., \& Wilson, P. (2006). Motor, visual and egocentric transformations in children with developmental coordination disorder. Child: Care, Health and Development, 32, 633-647. doi: 10.1111/j.1365-2214.2006.00688.x السلسل

Wilson, P. H., Ruddock, S., Smits-Engelsman, B. C., Polatajko, H. J., \& Blank, R. (2013). Understanding performance deficits in developmental coordination disorder: a meta-analysis of recent research. Developmental Medicine \& Child Neurology, 55, 217-228. doi: 10.1111/j.1469-8749.2012.04436.x المالسلس

Wolpert, D. M. (1997). Computational approaches to motor control. Trends in Cognitive Sciences, 1, 209-216. doi: 10.1016/S13646613(97)01070-X سلس

RECEIVED 29.02.2020 | ACCEPTED 23.12.2020 